Dhaka Univ. J. Biol. Sci. 24(2): 137-145, 2015 (July)

\title{
ANTAGONISTIC POTENTIAL OF RHIZOSPHERE MYCOFLORA AGAINST FUSARIAL WILT OF BRINJAL
}

\author{
Romana AKTer, K.S. Hossain ${ }^{1}$ AND M.A. BASHAR* \\ Department of Botany, University of Dhaka, Dhaka-1000, Bangladesh
}

Key words: Antagonist, Rhizosphere mycoflora, Brinjal, Fusarial wilt

\begin{abstract}
Antagonistic potentials of seven rhizoshere soil fungi viz., Aspergillus flavus Link., A. fumigatus Fresen., A. niger Tiegh., A. terreus Thom., Penicillium sp., Trichoderma harzianum Refat. and T. viride Pers. were tested against the Fusarium oxysporum Schlecht. and F. solani (Mart.) Sacc. - the two pathogens, isolated from wilted roots of brinjal plants. Out of seven soil fungi Trichoderma harzianum was found most effective to control the growth of both the test pathogens. More than $50 \%$ inhibition of the test pathogens were observed with T. viride, Aspergillus niger and A. fumigatus in colony interaction. The maximum inhibition of radial growth of the test pathogens was observed with volatile metabolites and cell free culture filtrates of Trichoderma harzianum. This fungus may be exploited commercially to control the disease.
\end{abstract}

\section{Introduction}

Brinjal or "Egg plant" (Solanum melongena L.) is the second most important vegetable crop next to potato in Bangladesh ${ }^{(1)}$. It is more or less available round the year and suffers from more than 10 different diseases. Among them, wilt has been treated as one of the major constrains in eggplant cultivation in the country. Along with some others Fusarium oxysporum Schlecht. and F. solani (Mart.) Sacc. - the two soil borne pathogens were reported as causal agents of the disease ${ }^{(2-4)}$. In the management strategy of plant diseases, use of biological control agents are now widely recognised especially against soil borne pathogens. Study of antagonist as biological control agent has now become one of the most exciting and rapidly developing areas in plant pathology because of its great potential to solve many agricultural and environmental problems ${ }^{(5,6)}$. It is now well known that the nature of root exudates determine the mycoflora of rhizosphere soil which is a massive reservoir of both beneficial and detrimental fungi. Hence, the present investigation was designed to evaluate antagonistic potentiality of some rhizosphere fungi in vitro against Fusarial wilt of brinjal.

*Author for correspondence: < botanybashar@yahoo.com>. ${ }^{1}$ Department of Botany, Jagannath University, Dhaka, Bangladesh. 


\section{Materials and Methods}

The pathogens were isolated from the roots of wilted egg plants following Tissue Planting method ${ }^{(5)}$. About $4 \mathrm{~mm}$ long, 50 inocula were prepared after sterilized their surface by $10 \%$ Clorox solution for one minute. This inocula were placed aseptically on PDA medium where a drop ( $c a .0 .03 \mathrm{ml}$ ) of lactic acid was added before plating to check the bacterial growth. Inoculated plates were incubated at $25 \pm 2^{\circ} \mathrm{C}$ for 7 days. The isolates were purified following serial dilution method(5), maintained on PDA slants and stored at $10 \pm 1.0^{\circ} \mathrm{C}$ in an refrigerator for further studies. Cultures were maintained by subculturing after four weeks of intervals. Identities of the pathogens were confirmed following the standard literature(6). The virulence of the isolated pathogens were tested following soil inoculation method where they were grown in maize meal agar medium and 4 weeks old seedling of the selected cultivar were transplanted in the inoculated soil. After 4 - 6 weeks, re-isolation of the causal agents were also done from the artificially inoculated wilted roots.

The soil fungi were isolated from the rhizosphere of several healthy brinjal crop fields following serial dilution method. For purification and maintenance of the isolates, same methods were followed as stated above. Identities of the soil fungi were confirmed following the standard literature ${ }^{(6-8)}$.

The antagonistic action of the seven selected soil fungi against the test pathogens were carried out by dual culture technique ${ }^{(9)}$, where, $5 \mathrm{~mm}$ blocks of each pathogen and selected soil fungus were placed $3 \mathrm{~cm}$ apart on PDA medium in paired combination. Interactions were assessed in terms of grades, intermingling zone and zone of inhibition. The interactions were recorded after 5 days of inoculation. The per cent growth inhibitions of the test pathogens owing to the presence of soil fungi, were calculated as follows:

$$
\text { Per cent growth inhibition }=\frac{\mathrm{r}_{1}-\mathrm{r}_{2}}{\mathrm{r}_{1}} \times 100
$$

where, $r_{1}$ denotes the radial growth of the test fungus towards the opposite side, $r_{2}$ denotes the radius of the test fungus towards the soil fungus.

To assays the effects of volatile substances of the soil fungi on the two test pathogens, each selected soil fungus was grown in $9 \mathrm{~cm}$ Petri plates on PDA medium. After 7 days, the lid of each Petri plate was replaced by the same size bottom plate, containing $15 \mathrm{ml}$ PDA medium, centrally inoculated with a test pathogen and was enclosed by three layers of parafilm, to prevent the loss of volatile substances. Control was also prepared in the same way but with the test pathogen at the bottom. After 7 days colony diameter of the test pathogen, in all sets, were measured.

To evaluate the effects of non-volatile substances present in the culture filtrates of the selected soil fungi on the two test pathogens, three $0.5 \mathrm{~mm}$ blocks each of individual soil 
fungi, cut from the actively growing margins of 5 days old cultures, were inoculated separately into $250 \mathrm{ml}$ conical flasks each containing $100 \mathrm{ml}$ sterilized potato dextrose broth medium. After 10 days of incubation the static cultures were filtered firstly through Whatman filter paper No. 44 and finally through Seitz filter by vacuum filter to obtain cell free culture filtrates. Before plating, requisite amount of this filtrate was mixed well with sterilized PDA medium separately to get final concentration of 5, 10 and 20\%. Each Petri plate was allowed to solidify and inoculated centrally with a $5 \mathrm{~mm}$ agar disc, cut from the margin of actively growing culture of a test pathogen. In control, Petri plate containing PDA medium and requisite amount of sterilized distilled water instead of culture filtrates were inoculated with a test pathogen as described above. After 7 days colony diameter of the test pathogen, in all sets, were measured.

The per cent inhibition of each test pathogen owing to the effects of volatile and non volatile substances of the soil fungi was calculated separately as follows.

$$
\mathrm{I}=\frac{\mathrm{C}-\mathrm{T}}{\mathrm{C}} \times 100
$$

where, $\mathrm{I}=$ Per cent growth inhibition, $\mathrm{C}=$ growth in control and $\mathrm{T}=$ growth in treatment.

All the Petri plates were incubated at $25 \pm 2^{\circ} \mathrm{C}$. Three replications were maintained in every trial. The results were statistically analyzed by ' $t$ ' test following Steel and Torrie ${ }^{(10)}$.

\section{Results and Discussion}

Two fungal pathogens namely, Fusarium oxysporum Schlecht. and F. solani (Mart.) Sacc. were isolated from the wilted brinjal roots following Tissue Planting method. They were found as virulent in the test of pathogenicity and grown the same two species on PDA when re-isolation was done from the inoculated wilted brinjal roots.

A total of 12 fungi, representing seven genera were isolated from the rhizosphere soil of brinjal. They were Aspergillus flavus Link, A. fumigatus Fresen., A. niger Tiegh., A. terreus Thom, Cladosporium sp., Curoularia lunata (Wakker) Boedijn, Fusarium oxysporum Schlecht., F. solani (Mart.) Sacc., Penicillium sp., Rhizopus sp., Trichoderma harzianum Rifai and T. viride Pers.. Among them 7 species under the genera Aspergillus, Penicillium and Trichoderma were selected for the test of antagonistic potentiality. These were collectively named as 'soil fungi'.

The results of colony interaction between the test pathogens and the soil fungi have been summarized in Table 1 and Fig. 1. Variation in antagonistic effects of the soil fungi were noted against the two test pathogens. It is evident that the antibiotic production varies depending on the organisms. Grade 3 was found to be the most commonly encountered type of colony interaction, grades 4 and 5 were recorded to be very infrequent. The intermingled zone between the soil fungi and test pathogens was very 
common. The maximum intermingled zone $(0.4 \mathrm{~cm})$ was observed in case of Aspergillus flavus and A. fumigatus against Fusarium oxysporum and Trichoderma harzianum against $F$. solani. All the soil fungi grew over the colony of the fungi except $A$. niger and $A$. terreus where inhibition zone was found 0.4 and $0.3 \mathrm{~cm}$, respectively.

Table 1. Colony interaction between the soil fungi and test pathogens in dual culture.

\begin{tabular}{|c|c|c|c|c|c|c|}
\hline Test pathogens & \multicolumn{3}{|c|}{ Fusarium oxysporum } & \multicolumn{3}{|c|}{ Fusarium solani } \\
\hline Soil fungi & $\mathrm{Gr}^{*}$ & $\begin{array}{l}\text { IMZ } \\
(\mathrm{cm})\end{array}$ & $\begin{array}{l}\text { IHZ } \\
(\mathrm{cm})\end{array}$ & $\mathrm{Gr}^{*}$ & $\begin{array}{l}\text { IMZ } \\
(\mathrm{cm})\end{array}$ & $\begin{array}{l}\text { IHZ } \\
(\mathrm{cm})\end{array}$ \\
\hline Aspergillus flavus & 3 & 0.4 & - & 3 & 0.2 & - \\
\hline A. fumigatus & 3 & 0.4 & - & 3 & 0.2 & - \\
\hline A. niger & 5 & - & 0.4 & 5 & - & 0.4 \\
\hline A. terreus & 4 & - & 0.3 & 4 & - & 0.2 \\
\hline Penicillium sp. & 3 & 0.3 & - & 3 & 0.3 & - \\
\hline Trichoderma harzianum & 2 & 0.2 & - & 2 & 0.4 & - \\
\hline T. viride & 2 & 0.2 & - & 2 & 0.3 & - \\
\hline
\end{tabular}

${ }^{*} \mathrm{Gr}=$ Grades from 1 (mutually intermingling growth) to 5 (mutual inhibition at a distance), based on Skidmore and Dickinson ${ }^{(12)} .2$ = Mutually intermingling growth where the fungus under observation has ceased growth and is being overgrown by another fugus. 3 = Intermingling growth where the fungus being observed is growing into the opposed fungus either above or below its colony. $4=$ Slight inhibition of both the interacting fungi with a narrow demarcation line $(1-2 \mathrm{~mm}) .5=$ Mutual inhibition of growth at a distance more than $2 \mathrm{~mm}$. $\mathrm{IMZ}=$ Intermingling zone, IHZ $=$ Inhibition zone, and ' - ' $=$ Not applicable. Results were significant at $\mathrm{p}=0.01$ to 0.05 in 't' test.

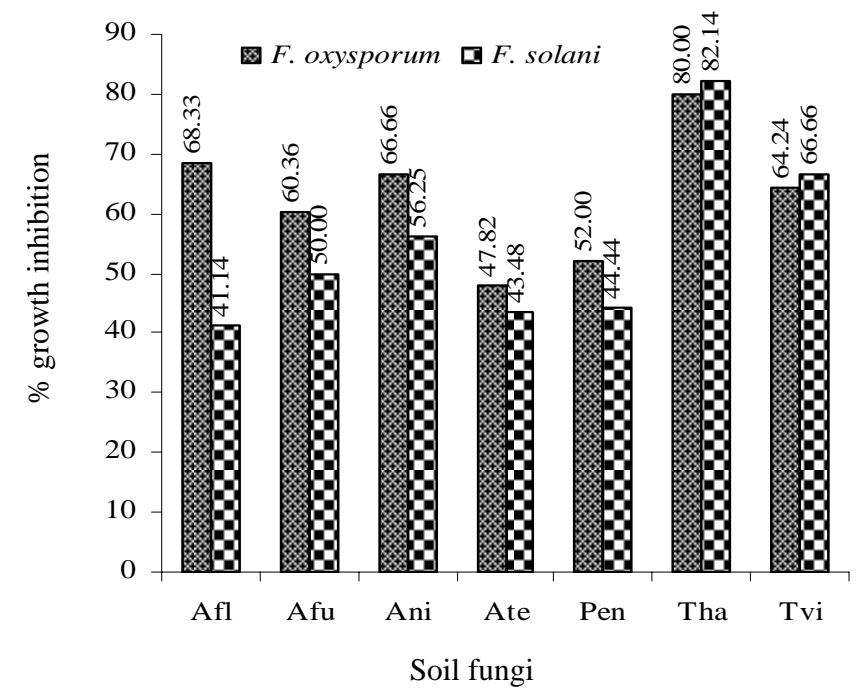

Fig. 1. Per cent growth inhibition of the test pathogens owing to the soil fungi in dual culture. Afl = Aspergillus flavus, $\mathrm{Afu}=A$. fumigatus, $\mathrm{Ani}=$ A. niger, Ate $=$ A. terreus, Pen $=$ Penicillium sp., Tha $=$ Trichoderma harzianum and Tvi $=T$. viride. Results were significant at $\mathrm{p}=0.01$ to 0.05 in ' $\mathrm{t}$ ' test. 
All the tested soil fungi inhibited the growth of all the test pathogens to varied degrees in dual culture experiments on agar plates (Fig. 1). In case of F. oxysporum, highest inhibition of radial growth was found in T. harzianum ( $80 \%$ ) followed by A. flavus (68.33\%) and A. niger (66.66\%). The maximum inhibition of radial growth of $F$. solani, was exhibited by T. harzianum ( $82.14 \%$ ) followed by T. viride (66.66\%) and A. niger (56.25\%).

Vinalea et al.(11) has reviewed tripartite interactions among Trichoderma-plantpathogen and showed that Trichoderma spp. produce numerous biologically active volatile and non-volatile compounds which might be responsible for the suppression of the two pathogens of brinjal wilt in the present study. Owing to fast growing nature, rapid sporulation and toxic metabolite producing capacity, Trichoderma spp. considered as potential antagonist. Hence, highest antagonistic activity of the T. harzianum was observed against the test pathogens in the present study.

It is clear from Fig. 2 that the volatile substances emanating from the cultures of the soil fungi inhibited the radial growth of both the test pathogens to varied degrees. Highest inhibition of radial growth of F. solani found was by T. harzianum (36.55\%) followed by T. viride (27.33\%) and A. niger (25.06\%), whereas, T. harzianum showed $31.30 \%$ inhibition of radial growth of $F$. oxysporum which was followed by $T$. viride (23.26\%) and A. niger (19\%). In case of each test pathogen A. flavus and A. fumigatus showed lesser degree of inhibition of radial growth of the test pathogens.

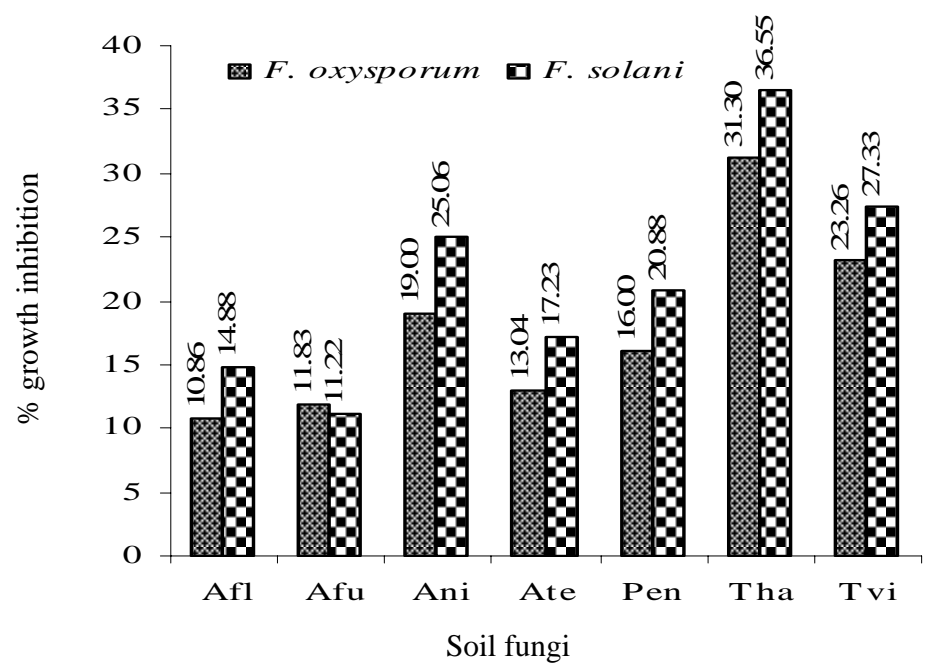

Fig. 2. Per cent growth inhibition of test fungi owing to volatile substances of the soil fungi. Abbreviations are same as in Fig.1. Results were significant at $p=0.01$ to 0.05 in ' $t$ ' test.

The growth inhibition of the test pathogens may be attributed to the presence of growth inhibitory substances in the volatile metabolites ${ }^{(12)}$. The gross effect may also depend on the interaction between the volatile factors of two fungi as some sort of 
chemical reaction may occur there, which may include the nullification of the metabolites by each other.

The present observation suggests that there were qualitative and quantitative differences in the volatile substances produced by various soil fungi as they exhibited different degrees of growth inhibition of the test pathogens. Dennis and Webster ${ }^{(13)}$ noted that certain Trichoderma spp. produced volatile antibiotics. These compounds inhibited the growth of Rhizoctonia solani, Pythium ultimum and Fusarium oxysporum. No lethality to any of the test pathogens was reported by these authors and comprehensive chemical analyses of the volatile components of the fungal cultures were not performed, although acetaldehyde was suggested as one of the volatiles. Some protective compounds recently isolated from endophytes are taxol, oocydin-A, cryptocin, ambuic acid and jesterone ${ }^{(14-17)}$. However, Hutchinson ${ }^{(18)}$ gave direct evidence by quantitative analysis of these volatiles.

Dennis and Webster ${ }^{(13)}$ detected the following substances from volatile fraction of culture filtrates of fungi: acetaldehyde, n-propanol, propionaldehyde, isobutanol, n-butyraldehyde, ethyl acetate, isobutyl acetate and acetone. Alcohols, esters, ketones of which 1-butanol, 3-methyl acetate, styrene, methyl isobutyl ketone, naphthalene and butylated hydroxytoluene, 1-butanol, 3-methyl- followed by 1-butanol, 3 methyl-acetate were detected from Muscodor albus, a novel endophytic fungus ${ }^{(19)}$.

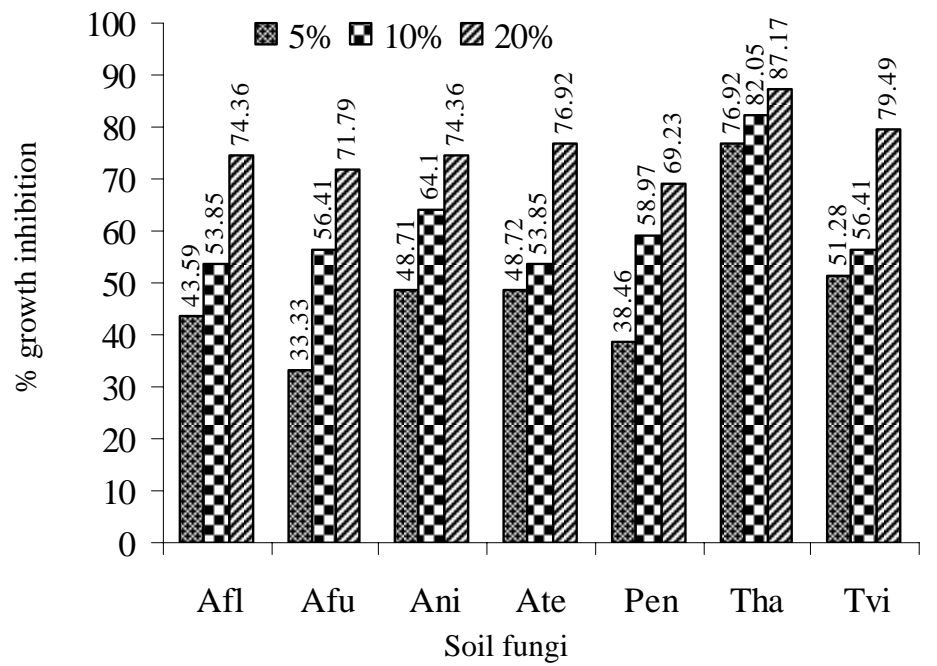

Fig. 3. Per cent growth inhibition of Fusarium solani owing to culture filtrates of the soil fungi at 5, 10 and $20 \%$ concentrations. Abbreviations are same as in Fig.1. Results were significant at p $=0.01$ to 0.05 in ' $\mathrm{t}$ ' test.

The Fig. 3 shows the effect of non-volatile metabolites on the growth of F. solani. All the antagonists showed varied degree of growth inhibition of the pathogen at different concentrations. Out of the seven antagonists, T. harzianum showed highest inhibition of 
the pathogen at all the concentrations tested. The inhibition of the pathogen increases with the increase of the concentration of the treatments. The order of effectiveness against $F$. solani at $20 \%$ concentration was $T$. harzianum $>T$. viride $>A$. terreus $>A$. niger $>$ A. flavus $>$ A. fumigatus and Penicillium sp.

Similarly, the maximum inhibition of radial growth of F. oxysporum was observed by T. harzianum at all the tested concentrations (Fig. 4). The order of effectiveness against $F$. oxysporum at $20 \%$ concentration was T. harzianum $>$ A. terreus $>$ T. viride $>$ Penicillum sp., A. fumigatus $>A$. niger and $A$. flavus. The inhibition of the radial growth of the test pathogens owing to non-volatile metabolites, may be attributed to the production of antibiotic substances in the culture filtrates and/or nutrient impoverishment ${ }^{(20-22)}$.

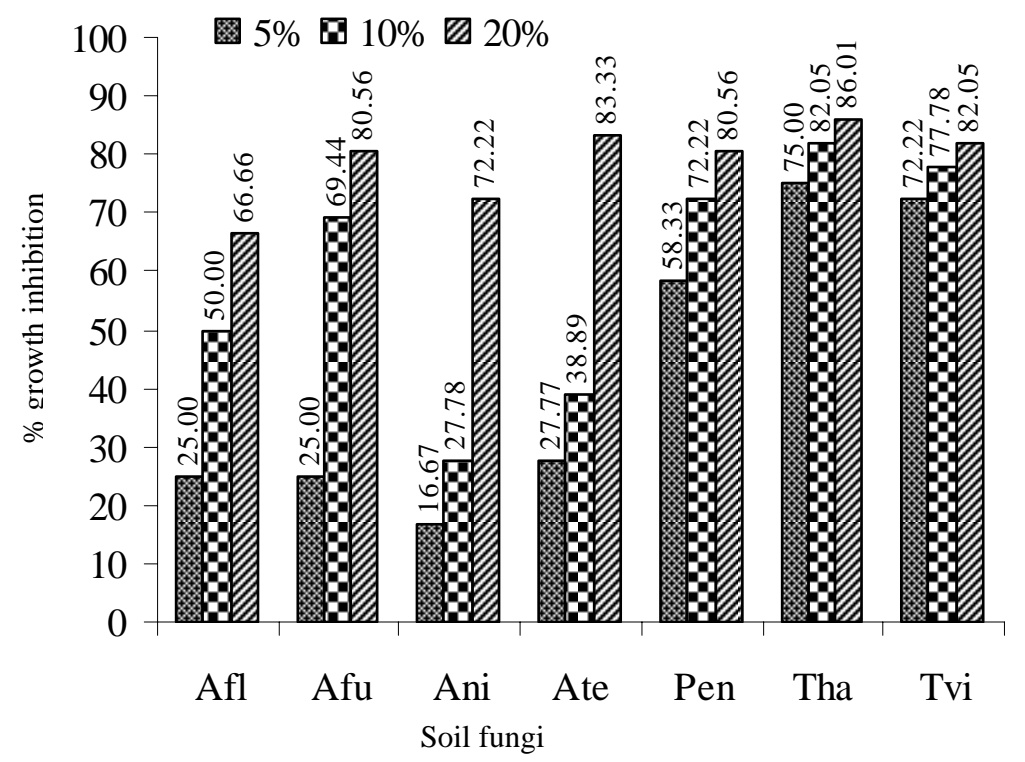

Fig. 4. Per cent growth inhibition of Fusarium oxysporum owing to culture filtrates of the soil fungi at 5, 10 and $20 \%$ concentrations. Abbreviations are same as in Fig.1. Results were significant at $\mathrm{p}=0.01$ to 0.05 in ' $\mathrm{t}$ ' test.

Figs 1 - 4 show that out of seven soil fungi Trichoderma harzianum was found most effective to control the growth of both the test pathogens. Akter et al.(23) also found the same results against six pathogenic fungi viz., Colletotrichum sp., Curvularia lunata, Fusarium moniliforme, F. oxysporum, F. semitectum and Phomopsis sp. isolated from different leaf spots and fruit rots of brinjal. The figures also show that none of the soil fungi could inhibit the growth of the test pathogens completely. The per cent inhibition of the test pathogens against the soil fungi also differed. The differences might be owing to differences in nature, quality and quantity of the inhibitory substances produced by the soil fungi. 
The present observation suggests that Trichoderma harzianum may be exploited commercially as a control agent of Fusarial wilt of brinjal.

\section{References}

1. Anonymous 2005. Year Book of Agricultural Statistics of Bangladesh. Statistics Division, Bangladesh Bureu of Statistics (Monthly Statistical Bulletin, Bangladesh, December 2003). Ministry of Planning, Government of the People's Republic of Bangladesh. pp. 55.

2. Rahman MA, F Ali, KMA Hossain and L Laila 2011. Screening of different eggplant cultivars against wilt disease caused by fungi, bacteria and nematodes. J. Exp. Sci. 2(1): 6-10.

3. Talukdar MJ 1974. Plant diseases in Bangladesh. Bangladesh J. Agric. Res. 1(1): 61-86.

4. Bhadauria BP, Y Singh, S Puri and PK Singh 2012. Eco-friendly management of Fusarium wilt of brinjal. Ecology, Environment and Conservation Paper. 18(4): 1049-1052.

5. Aneja KR 2003. Experiments in Microbiology, Plant Pathology and Biotechnology. $4^{\text {th }}$ ed. New Age Pub., New Delhi. pp. 607.

6. Gilman JC 1967. A Manual of Soil Fungi. Oxford and IBH Publishing Co., New Delhi, $2^{\text {nd }}$ edition (Revised), pp. $x+450$.

7. Thom C and KB Raper 1945. A Manual of the Aspergilli. The Williams \& Wilkins Company, Baltimore, USA.

8. Barnett HL and BB Hunter 1972. Illustrated Genera of Imperfect Fungi. Burgess Pub. Co. U.S.A. pp. iii +241.

9. Skidmore AM and CH Dickinson 1976. Colony interaction and hyphal interference between Septoria nodorum and phylloplane fungi. Trans. Br. Mycol. Soc. 66: 57-64.

10. Steel RGD and JH Torrie 1960. Principles and Procedures of Statistics. McGraw Hill Book Co., New York. pp. xvi +481.

11. Vinalea F, K Sivasithamparamb, EL Ghisalbertic, R Marraa, SL Wooa and M Loritoa 2008. Trichoderma-plant-pathogen interactions. Soil Biology and Biochemistry 40: 1 - 10.

12. Morath SU, R Hung and JW Bennett 2012. Fungal volatile organic compounds: A review with emphasis on their biotechnological potential. Fungal Biol. Rev. 26: 73 - 83.

13. Dennis C and J Webster 1971. Antagonistic properties of species groups of Trichoderma II. Production of volatile antibiotics. Trans. Br. Mycol. Soc. 57: 41- 48.

14. Stierle A, G Strobel and D Stierle 1993. Taxol and taxane production by Taxomyces andreanae, an endophytic fungus of Pacific yew. Science 260: 214-216.

15. Strobel GA, JY Li, F Sugawara, H Koshino, J Harper and WM Hess 1999. Oocydin A, a chlorinated macrocyclic lactone with potent anti-oomycete activity from Serratia marcescens. Microbiol. 145: 3557-3564.

16. Li JY, GA Strobel, J Harper, E Lobkovsky and J Clardy 2000. Cryptocin, a potent tetramic acid antimycotic from the endophytic fungus Cryptosporiopsis cf. quercina. Org. Lett. 2: 767-770.

17. Li JY and GA Strobel 2001. Jesterone and hydroxy-jesterone antioomycete cyclohexenone epoxides from the endophytic fungus Pestalotiopsis jesteri. Phytochem. 57: 261-265.

18. Hutchinson SA and ME Cowan 1972. Identification and biological effects of volatile metabolites from cultures of Trichoderma harzianum. Trans. Br. Mycol. Soc. 59: 71-77. 
19. Gary A, SE Dirkse, J Sears and C Markworth 2001. Volatile antimicrobials from Muscodor albus, a novel endophytic fungus. J. Microbiol. 147: 2943 - 2950.

20. Kexiang G, L Xiaoguang, L Youghong, Z Tianbo and W Shuliang 2002. Potential of Trichoderma harzianum and T. atroviride to control Botryosphaeria berengeriana $\mathrm{f}$. sp. piricola, the cause of apple ring rot. Phytopathol. 150: 271-276.

21. Wool SL and M Larito 2007. Exploiting the interactions between fungal antagonists, pathogens and the plant for biocontrol. In: Novel Biotechnologies for Biocontrol Agent Enhancement and Management. Vurro M and J Gressel (Eds.). Springer Press, Amsterdam, Netherland. pp. 425.

22. Howell CR 2003. Mechanisms employed by Trichoderma species in the biological control of plant diseases: The history and evolution of current concepts. Plant Dis. 87: 4-10.

23. Aktar MT, KS Hossain and MA Bashar 2014. Antagonistic potential of rhizosphere fungi against leaf spots and fruit rot pathogens of brinjal. Bangladesh J. Bot. 43(2): 213-217.

(Manuscript received on 5 April, 2015; revised on 4 June, 2015) 